\title{
FACTORS THAT INFLUENCE SOCIAL MEDIA USAGE IN TRAVEL INFORMATION INTERNET SEARCHES
}

\author{
NOR FAZZIATUL AZNI MOHD ISA, N ALIA FAHADA W AB RAHMAN* AND \\ MONIZAIHASRA MOHAMED
}

Faculty of Business, Economics and Social Development, Universiti Malaysia Terengganu, 21030 Kuala Nerus, Terengganu, Malaysia.

*Corresponding author: n.alia@umt.edu.my

http://doi.org/10.46754/umtjur:2021.10.001

\begin{abstract}
Advances in technological development, especially with regards to mobile technology and applications, sees more and more tourists being prone to using social media to gather valuable travel and destination information particularly in the travel planning phase. This is in line with the theory of reasoned action, information reliability and enjoyment, which are some of the benefits that are positively associated with the intention to use social media. Most people, especially teenagers, are twice as likely to have profiles on social media and use it as a source to gather information on travel and destinations they would like to visit. Thus, this study examines the factors that influence the use of social media in travel information searches by students. The main objective of this study is to examine students' intentions to use social media in travel information searches. Specifically, this study attempts to determine how perceived benefits (information reliability, enjoyment) influence travel information searches on social media. Data for the study was gathered at public universities in Malaysia using convenience sampling and questionnaires.
\end{abstract}

Keywords: Social media, travel information search, intention to use, pre-trip phase.

\section{Introduction}

Social media is widely used by tourists and travellers at different stages of the tour or travel experience, including the pre-trip, during-thetrip and post-trip stages (Leung et al., 2013). At the pre-visit stage, which is associated with travel planning, social media is considered a reliable tool for tourists to obtain first-hand accounts and benefit from the experiences of other tourists or travellers that have visited the destination before and this will assist them with the creation of realistic expectations about the destination in question (Sigala et al., 2012).

At the during-the-trip stage, social media allows en-route travel information searches and enables tourist to simultaneously share their experiences in real-time (Gretzel et al., 2013). This allows other tourists, or potential tourists, to be aware instantly of changes to the weather, service levels, state of the amenities on location, which may affect their travel plans.
Finally, at the post-visit stage, many people engage with social media to share and communicate their experiences (Pan et al., 2018).

Social media not only plays a significant role for tourists at each stage of the experience, but also plays a crucial function as an effective means of communication for the operations and management of amenities and events at the destinations in question. For instance, social media allows tourism service providers to actively communicate with end-users of their tourism products, tourism companies are also able to simultaneously respond to feedback from the guests or tourists in real-time on the same social media platforms (Dinçer \& Alrawadieh, 2017). Thus, social media can help these businesses gather customer feedback and assist them in making reasonable improvements the to their services in the future (Jonassen et al., 2003; Leung et al., 2013). 
Social media has also been recognised as a more effective promotional tool compared to traditional advertising. This is due to the lower costs involved and the quicker response times between when the communication reaches the targeted audience and receives a response (Roult et al., 2016). Therefore, it is no surprise why social media is the main choice for travel companies to advertise their travel packages.

They trust and use social media as a major medium to facilitate search for customers looking for places to travel, hotels, delicious eateries and so on.

Social media has also been acknowledged as an effective go between for tourism service providers and the tourists themselves. Social media allows tourism service providers, such as travel agents and destination markets to connect and communicate among themselves and build working relationships with potential and actual tourists (Oz, 2015). Thus, social media is considered an interactive platform for information dissemination and consumption in the tourism industry (Benckendorff et al., 2014; Gretzel \& Yoo, 2013; Law et al., 2014).

The notable wide usage of social media has transformed almost all tourismrelated industries. As a consequence, these advancements have had a significant influence on the tourism industry environment including operational, management and marketing (Law et al., 2014).

From a travel and tourism context, social media apps on smart-devices are widely recognised as a reliable and significant resource and point of interaction for travel planning purposes, with search engines providing direct access to information.

Although their importance and value have been acknowledged, studies conducted on the usage of social media as a source and resource for travel information searches is still limited. Thus, this study will examine the factors that influence social media use in travel information Internet searches. Apart from that, there is limited available literature on social media and its influence on travel information research (Rupak et al., 2014).

Moreover, there is a lack of understanding regarding the factors that affect customer engagement on social media sites and intention to continue using it (Hussein \& Hassan, 2017). Therefore, this study will focus on the factors that influence the use of social media in travel information Internet searches among UMT students.

More specifically, this study will investigate the influence of perceived benefits (information reliability, enjoyment), perceived sacrifice (complexity, effort) and subjective norms on students' travel information search using social media. This study attempts to answer these research questions:

1) What are the factors influencing travel information Internet searches using social media?

2) What are the most significant factors that influence travel information Internet searches using social media?

\section{Literature Review}

\section{Travel Information Internet Searches}

The widespread use of Web applications and the increasing number of social media applications during the last decade have given a new shape to the tourism destination promotion. Facebook, the world's largest social network who boast of a massive 1.35 billion active users on its network in the beginning of October 2014 (Facebook, 2014) really influence the travel planning process which include travel information Internet searches about everything at that destination.

Social Media is assuming an inexorably vital part as information sources for travellers. Social media is getting progressively more relevant as part of tourism practices affecting destinations and businesses. For experience sharing, social media is predominantly used after holidays. Research also shows that there is a strong correlation between perceived level 
of influence from social media and changes made in holiday plans prior to final decisions. Moreover, it is revealed that user-generated content is perceived to be more trustworthy than official tourist websites, travel agents and other forms of mass media advertising (Fortis, Buhalis \& Rossides, 2012).

\section{Theory of Reasoned Action (TRA)}

Theory of reasoned action (TRA) provides a model that has potential benefits for predicting the intention to perform a behaviour based on an individual's attitudinal and normative beliefs (Azjen \& Fishbein, 1969,1980).

\section{Social Media}

Social media is described as a platform for people with common interest to share and communicate their opinions and activities (Miguens et al., 2008; Del Chiappa, 2013). In tourism context, people usually share their experiences after the trip is completed which covers a broad area, including cost and budget, transportation, accommodation, food and many more (Pan et al., 2018). The two-way communication provided by the social media platforms allows people to keep connected and create relationship with the people that shared the same interest (Pühringer \& Taylor, 2008).

\section{Information Reliability}

Reliability is described as trust, trustworthiness, accuracy among others (Hilligoss \& Rieh, 2008; Metzger et al., 2003). Information reliabilities allow tourists to identify, search, gather, communicate and understand information regarding a specific destination. According to Sigala (2012), information reliability is a crucial factor which tourists appreciate when engaging in Internet searches on social media.

\section{Enjoyment}

Enjoyment is defined as the extent to which a person perceives that engaging in social media offers enjoyment and the perceived enjoyment is related to the engagement (Wang, 2012). According to Van der Heijen (2004), social media offers entertainment and assists people to use their imagination as a form of escapism from a stressful life. Perceived enjoyment has been found to positively influence technology acceptance (Teo et al., 1999; Venkatesh, 2000; van der Heijden, 2004; Lin \& Lu, 2011). Muntinga et al. (2011) further explain that enjoyment, relaxation and passing time are the main reasons for people engaging in social media.

Thus, the research hypotheses for this study are as follows:

H1: There is a positive effect between information reliability and travel information Internet searches using social media.

$\mathrm{H} 2$ : There is a positive effect between enjoyment and travel information Internet searches using social media.

\section{Method}

\section{Approach and Data Collection}

This study adopts quantitative research approach. Quantitative research was completed through a survey using an online questionnaire. An online survey was done at one of the public universities in Malaysia, namely Universiti Malaysia Terengganu (UMT). Only one university was selected due to the time constraints that the researchers faced in completing the study as part of their final year thesis project.

Convenience sampling was used as this method is the easiest because respondents were selected based on their ready availability and willingness to take part in the survey. A link was sent to the student's email, and a follow up reminder will be sent a week after the initial email to encourage a response. The population of this study included all UMT the students' regardless course of their study, which was 8861 students. The population of the study was obtained from Student and Alumni Affairs, Universiti Malaysia Terengganu. 
The final sample population of this study was 400 students from UMT. Researchers used Raosoft to calculate the ideal sample size from total student population of 8861 students and obtained 369 respondents.

Data analysis. This study used Statistical Package for the Social Sciences (SPSS) technique to analyse data. Multiple Regression Analysis (MRA), Descriptive and Frequency was used to identify the relationship between the dependent and independent variables.

\section{Measures}

The measures used in this study are based on research and data gathered from available literature relating to the three constructs of information reliability, enjoyment and social media use for travel information Internet searches. Four information reliability items were adapted from a study done by Ha and Ahn (2011), seven enjoyment items were adapted from a study conducted by Wu and Chang (2005) and Van der Heijden (2003) and three social media usages for travel information Internet search items were adapted from the research of Vogt and Fesenmaier (1998). Likert 5-point scale was used to measure each item varying from strongly disagree (1) to strongly agree (5).

\section{Conclusion}

The findings are expected to provide an understanding of the factors that influence the use of social media in travel information searching. The attributes of information in social media and hedonic aspects of social media are expected to have a positive influence on the reason of why tourists and potential tourists use social media in the travel planning phase. Some practical implications are expected from this study. For instance, destination marketers can improve their attributes of social media information shared in social media in order to meet the tourists and potential tourists' preferences in referring to social media during the travel planning phase. Furthermore, travel agents may improve their usage of social media by maximising the value of information shared on social media based on the tourists' preferences.

\section{Acknowledgements}

The Authors wish to thank Universiti Malaysia Terengganu (UMT) for the research opportunity and the anonymous reviewers for their insightful comments and suggestions.

\section{References}

Ajzen, I. (1991). The theory of planned behaviour, Organizational Behavior and Human Decision Processes, 50(2),179-211.

Ajzen, I., \& Fishbein, M. (1980), Understanding Attitudes and Predicting Social Behaviour, Prentice- Hall, Englewood Cliffs, NJ.

Andrews, D., Nonnecke, B., \& Preece, J. (2003). Electronic Survey Methodology: a Case Study in Reaching Hard To Involve Internet Users, International Journal of HumanComputer Interaction. 16(2), 185-210.

Buhalis, D., \& Law, R. (2008). Progress in information technology and tourism management: 20 years on and 10 years after the Internet-The state of eTourism research. Tourism Management, 29(4), 609623.

Cantallops, A. S., \& Salvi, F. (2014). New consumer behavior: A review of research on eWOM and hotels. International Journal of Hospitality Management, 36,41-51.

Chong, A.Y.L. (2013). Predicting m-commerce adoption determinants: a neural network approach, Expert Systems with Applications, 40(2), 523-530.

Daniel, L., Rob. L., Hubert, V.H., \& Dimitrios, B. (2013) Social Media in Tourism and Hospitality: A Literature Review, Journal of Travel \& Tourism Marketing, 30(1-2), 3-22.

Del Chiappa, G. (2011). Trustworthiness of Travel 2.0 applications and their influence on tourist behav- iour: An empirical investigation in Italy. In Law, R., Fuchs, M., \& Ricci, F. (Eds.), Information and communication technologies in tourism (pp. 331-342). New York, NY: Springer. 
Dinçer, M.Z., \& Alrawadieh, Z. (2017). Negative Word of Mouse in the Hotel Industry: A Content Analysis of Online Reviews on Luxury Hotels in Jordan, Journal of Hospitality Marketing \& Management, 26(8), 785-804.

Ha, S., \& Ahn, J. (2011). Why are you sharing others' tweets? The impact of argument quality and source credibility on information sharing behavior. In: ICIS 2011 Proceedings, pp. 1-11.

Hilligoss, B., \& Rieh, S.Y. (2008). Developing a unifying framework of credibility assessment: construct, heuristics, and interaction in context, Information Processing \& Management, 44 (4), 1467 1484.

Hussein, R., \& Hassan, S. (2017). Customer engagement on social media: how to enhance continuation of use. Online Information Review, 41(7),1006-1028.

Johnson, B., \& Christensen, L. (2008). Educational research: Quantitative, qualitative, and mixed approaches (p. 34). Thousand Oaks, CA: Sage Publications.

Jonassen, D. H., Howland, J., Moore, J., \& Marra, R. M. (2003). Learning to solve problems with technology: A constructivist perspective (2nd ed.). Columbus, $\mathrm{OH}$ : Merrill/Prentice-Hall.

Lee, Y.J., \& Gretzel,U. (2014) Cross-Cultural Differences in Social Identity Formation through Travel Blogging, Journal of Travel \& Tourism Marketing, 31(1), 37-54.

Muntinga, D.G., Moorman, M., \& Smit, E.G. (2011), Introducing COBRAs, International Journal of Advertising, 30(1), 13-46.

Pühringer, S., \& Taylor, A. (2008). A practitioner's report on blogs as a potential source of destination marketing intelligence. Journal of Vacation Marketing, 14(2), 177187. doi: 10.1177/1356766707087524
Roult, R., Gaudette, M., Denis, A., \& Adjizian, J.M. (2016). Site management and use of social media by tourism businesses: the case of Quebe. Czech Journal of Tourism, 5(1), 21-34.

Rupak, R., Rawski.G., Yang, J., \& Johnson, B. (2014). Technology acceptance model (TAM) and social media usage: an empirical study on Facebook, Journal of Enterprise Information Management, 27(1), 6-30.

Sigala, M., Christou, E., \& Gretzel, U. (2012). Social Media in Travel, Tourism and Hospitality: Theory, Practice, and Cases. Printed and Bound in Great Britain by the MPG Books Group, UK.

Teo, T.S.H., Lim, V.K.G., \& Lai, R.Y.C. (1999). Intrinsic and extrinsic motivation in internet usage. International Journal of Management Science, 27, 25-37.

Valaei, N., Rezaei, S., Ismail, W.K.W., \& Oh, Y.M. (2016), The effect of culture on attitude towards online advertising and online brands: applying Hofstede's cultural factors to internet marketing, International Journal of Internet Marketing and Advertising, 10 (4), 270-301.

van der Heijden, H. (2004), "User acceptance of hedonic information systems", MIS Quarterly, Vol. 28 No. 4, pp. 695-704.

Venkatesh, V. (2000). Determinants of perceived ease of use: integrating control, intrinsic motivation, and emotion into the technology acceptance model, Information Systems Research, 11(4), 342-365.

Vogt, C.A., \& Fesenmaier, D.R., (1998). Expanding the functional information search model. Annals of Tourism Research, 25 (3), 551-578.

Wang, Y.S., Lin, H.H., \& Liao, Y.W. (2012). Investigating the individual difference antecedents of perceived enjoyment in students' use of blogging. British Journal of Educational Technology, 43(1), 139-152. 
